\title{
DESKRIPSI PENGETAHUAN IBU TENTANG KB SUNTIK 3 BULAN (DEPO PROGESTIN) DI PUSKESMAS BONTOBAHARI BULUKUMBA
}

\author{
Sitti Usmia, Haerani ${ }^{1}{ }^{*}$, Sri wahyuni ${ }^{1}$, Mudyawati Kamaruddin ${ }^{1}$, Misriyani $^{2}$
}

\author{
${ }^{1}$ Program Studi Kebidanan, Akademi Kebidanan Tahirah Al Baeti, Bulukumba, Sulawesi Selatan, \\ ${ }^{2}$ Fakultas Kedokteran, Universitas Alkhairaat, Jl. Diponegoro Palu 94221, Sulawesi Tengah, Indonesia \\ *Corresponding author: Telp: +6285242473342, email: haeranirani987@gmail.com
}

\begin{abstract}
ABSTRAK
Kontrasepsi suntikan progestin adalah kontrasepsi yang mencegah terjadinya kehamilan dengan cara disuntik intra-muskuler yang berdaya kerja 3 bulan dan tidak membutuhkan pemakaian setiap hari yang mengandung hormon progesteron dan tidak mengganggu proses produksi Air Susu Ibu (ASI). Tujuan. Penelitian ini adalah untuk mengetahui deksripsi pengetahuan ibu tentang KB suntik 3 bulan (depo progestin) yang meliputi pengertian, waktu penggunaan, efek samping, keuntungan dan kerugian. Metode penelitian yang digunakan adalah jenis penelitian deskriptif, lokasi peelitian di Puskesmas Bontobahari Kabupaten Bulukumba. Teknik pengambilan sampel dengan cara total sampling dengan jumlah sampel 38 responden, instrument penelitian menggunakan lembar tes. Hasil penelitian terhadap 38 responden di Puskesmas Bontobahari Kab. Bulukumba menunjukkan responden yang berpengetahuan baik sebanyak 15 orang $(39,48 \%)$, berpengetahuan cukup adalah 13 orang $(34,21 \%)$ dan yang kurang sebanyak 10 orang $(26,31 \%)$. Tingkat pengetahuan responden dibagi menjadi pengetahuan terhadap pengertian yaitu $81,58 \%$, waktu penggunaan depo progestin ialah $76,31 \%$, efek samping kategori baik $76,31 \%$, keuntungan depo progestin sebesar 78,94\% dan kerugian depo progestin adalah 78,94\%. Disimpulkan bahwa Tingkat pengetahuan ibu tentang KB suntik 3 bulan (depo progestin) di Puskesmas Bontobahari Kabupaten Bulukumba memiliki tingkat pengetahuan mayoritas baik yang mungkin dipengaruhi oleh beberapa faktor utama, seperti tingkat umur, pendidikan dan pekerjaan.
\end{abstract}

Kata kunci :Pengetahuan, Kelurga Berencana, Depo Progestin

\begin{abstract}
Progestin injection contraception is a type of contraception that prevents pregnancy contains progesterone hormone which is working for 3 months by intra-muscular injection. The advantage of the contraception is that it does not require daily use and does not interfere with the production process of breast milk. This study was to determine the description of maternal knowledge about 3-month injection contraception (depo progestin) which includes understanding, time of use, side effects, advantages and disadvantages. This type of research was descriptive, the study location was in Bontobahari Community Health Center, Bulukumba Regency. Sampling used the total sampling technique with 38 respondents, with instrument research by a questionnaire. The results showed that there were $39.48 \%$ (15 respondents) who have a good knowledge of depo progestin, $34.21 \%$ (13 people) was enough knowledge level, and only 26,31\% (10 people) who have less knowledge of depo progestin. Then, the knowledge level of respondents was divided into knowledge of understanding that was $81.58 \%$, the time of using depo progestin was $76.31 \%$, side effects of depo progestin was $76.31 \%$, the advantages and disadvantages of depo progestin were $78.94 \%$ and $78.94 \%$ respectively. All of which are in good category. Knowledge level of respondents about 3 month injection contraception (depo progestin) in Bontobahari health centre Bulukumba district generally has a good category. It might be influenced by several main factors such as age, education and employment.
\end{abstract}

Keyword :Knowledge, KB, Depo progestin

\section{PENDAHULUAN}

Pelayanan keluarga berencana (KB) sudah digalakkan oleh pemerintah Indonesia, dalam kenyataannya laju pertumbuhan penduduk di Indonesia masih tinggi.Salah satu faktor penyebabnya adalah pemilihan metode kontrasepsi yang tidak tepat.Banyak kesulitan yang dialami para wanita dalam menentukan kontrasepsi yang sesuai untuk dirinya.Kendala yang sering ditemukan timbul akibat kurangnya pengetahuan. Banyak aspek yang harus dipertimbangkan dalam pemilihan kontrasepsi yang meliputi derajat status 
kesehatan, kemungkinan munculnya efek samping, kegagalan atau kehamilan yang tidak dikehendaki, jumlah kisaran keluarga yang diharapkan, persetujuan dari suami atau istri, nilai-nilai budaya, lingkungan serta keluarga dan lain sebagainya (Affandi dkk., 2014).

Program keluarga berencana (KB) merupakan salah satu usaha kesehatan preventive yang paling dasar bagi wanita, peningkatan dan perluasan pelayanan KB merupakan salah satu usaha untuk menurunkan angka kesakitan dan kematian ibu yang sedemikian tinggi akibat kehamilan dan melahirkan. Berkembangnya teknologi ketersedian layanan KB bagi perempuan terdapat metode kontrasepsi yang paling banyak digunakan di Indonesia adalah jenis suntik dan implant atau susuk (Ayu, 2006). Kamaruddin dkk. (2020) telah melaporkan hasil penelitian terkait penggunaan metode kontrasepsi implant melalui penggalian sumber informasi yang sangat berperan penting untuk menyebarkan informasi dan pengetahuan tentang metode kontrasepsi implant di Wilayah Puskesmas Ponre Kecamatan Gantarang Kabupaten Bulukumba.

Salah satu jenis kontrasepsi efektif yang menjadi pilihan oleh pasangan usia subur (PUS) adalah KB Hormonal suntikan (injectables), dan merupakan salah satu alat kontrasepsi yang berdaya kerja panjang (lama), yang tidak membutuhkan pemakaian setiap hari. Kontrasepsi yang baik adalah aman, dapat diandalkan, sederhana, murah, dapat diterima orang banyak, dan tidak mengganggu proses produksi ASI. Pada umumnya akseptor lebih memilih metode kontrasepsi suntik, karena alasan praktis yaitu sederhana dan tidak perlu takut lupa. Kontrasepsi suntik memiliki efektifitas yang tinggi bila penyuntikan dilakukan secara teratur dan sesuai jadwal yang telah ditentukan (Astuti, 2010).

Kontrasepsi suntik progestin adalah mencegah terjadinya kehamilan dengan cara disuntik intra muskuler yang berdaya kerja 3 bulan dan tidak membutuhkan pemakaian setiap hari yang mengandung hormon progesteron dan tidak mengganggu proses produksi ASI. Kontrasepsi suntik adalah kontrasepsi berupa cairan, yang hanya berisi hormone progesterone disuntikkan ke dalam tubuh wanita secara periodik.Kontrasepsi suntik digunakan adalah noretisteron Enentat, Depo Medroksi Progesteron Asetat (DMPA), cyclofem.Salah satu kontrasepsi modern yang sering digunakan DMPA yang berisi depo medroksi progesterone asetat sebanyak $150 \mathrm{mg}$ dengan daya guna 3 bulan (Saefuddin dkk, 2010).
Berdasarkan data cakupan peserta $\mathrm{KB}$ aktif di Indonesia pada tahun 2017 dengan jumlah pasangan usia subur (PUS) sebanyak 37.338.265 dengan peserta KB aktif 23.606.218 $(63,22)$ meliputi IUD sebanyak 1.688.685 (7,15\%), MOW sebanyak $655.762(2,78 \%)$, MOP sebanyak $124,262 \quad(0,53 \%$, Implan sebanyak 1.650.227 $(6,99 \%)$, Suntik 14.817.663 (62,77\%), kondom sebanyak 288,388 (1,22\%) dan pil sebanyak 4.069.844 (17,24\%) (Kemenkes RI, 2017).

Data Dinas Kesehatan Kabupaten Bulukumba presentase cakupan Peserta KB aktif di wilayah Puskesmas Bontobahari pada tahun (2017) dengan jumlah sasaran pasangan usia subur (PUS) sebanyak 4622, peserta baru KB sebanyak $340(7,4 \%)$, peserta KB aktif $2912(63,0 \%)$, yang meliputi pengguna KB suntik sebanyak 1680 $(56,03 \%)$, kondom sebanyak 51 (1,85\%), pil sebanyak 967 (35,78\%), AKDR/IUD sebanyak 34 (1,04\%), implant sebanyak 158 (4,52\%), MOW sebanyak $22(0,78 \%)$, dan MOP 0 (0,00\%) (Dinkes Kab.Bulukumba, 2017).

Dari fenomena data yang ada maka, peneliti tertarik untuk meneliti dengan judul "Gambaran pengetahuan ibu tentang $K B$ suntik 3 bulan (depo progestin) di Puskesmas Bontobahari Kec. Bontobahari Kab. Bulukumba".

\section{METODOLOGI}

Penelitian ini merupakan penelitian deskriptif dengan pendekatan survey, sedangkan dalam penarikan sampel menggunakan metode non probality sampling dengan teknik Accidental sampling, yaitu teknik penentuan sampel berdasarkan faktor spontanitas, artinya siapa saja yang tidak sengaja bertemu dengan peneliti dan sesuai dengan karakteristik maka orang tersebut dapat digunakan sebagai sampel (responden) (Notoadmodjo, 2012).

Populasi adalah keseluruhan obyek penelitian yang memiliki karakteristik tertentu yang ditetapkan oleh peneliti untuk dipelajari kemudian ditarik kesimpulannya (Hidayat, 2014).Populasi dalam penelitian ini adalah ibu pengguna $\mathrm{KB}$ suntik 3 bulan (depo progestin) di puskesmas Bontobahari Kec. Bontobahari Kab. Bulukumba sebanyak 153. Jumlah sampel dalam penelitian ini di hitung menggunakan rumus (Arikunto, 2013) jika populasi kurang dari 100 lebih baik diambil semua, tetapi jika populasi lebih dari 100 dapat diambil $10 \%-15 \%$ atau $20 \%-25 \%$ atau lebih sehingga dari 153 menjadi 38 orang $(25 \%)$. 


\section{HASIL PENELITIAN DAN PEMBAHASAN Hasil Penelitian}

Pelaksanaan Penelitian ini dimulai dari tanggal 10 April sampai dengan 10 Mei 2019.Penelitian ini dilakukan untuk mengetahui gambaran pengetahuan ibu tentang KB suntik 3 bulan (depo progestin) di Puskesmas Bontobahari Kec. Bontobahari Kab. Bulukumba.

\section{1) Karakteristik Responden}

Tabel 4.1 Distribusi Frekuensi Pengguna KB Suntik 3 Bulan (Depo Progestin) Berdasarkan Umur di Puskesmas Bontobahari Kec. Bontobahari Kab. Bulukumba.

\begin{tabular}{ccc}
\hline Umur & $(\mathbf{F})$ & $\mathbf{( \% )}$ \\
\hline$<20$ & 1 & 2,63 \\
$20-35$ & 20 & 52,63 \\
$>35$ & 17 & 44,74 \\
\hline Jumlah & $\mathbf{3 8}$ & $\mathbf{1 0 0}$ \\
\hline
\end{tabular}

Sumber : Data Primer Tahun 2019

Berdasarkan tabel 4.1 didapatkan hasil bahwa dari total 38 responden umur ibu 20-35 tahun yang dominan sebanyak 20 orang $(52,63 \%)$ di bandingkan dengan umur yang lain yaitu $<20$ tahun sebanyak 1 orang $(2,63 \%)$, umur $>35$ tahun sebanyak 17 orang $(44,74 \%)$.

Tabel 4.2 Distribusi Frekuensi Pengguna KB Suntik 3 Bulan (Depo Progestin) Berdasarkan Pekerjaan di Puskesmas Bontobahari Kec. Bontobahari Kab. Bulukumba.

\begin{tabular}{ccc}
\hline Pekerjaan & $(\mathbf{F )}$ & $\mathbf{( \% )}$ \\
\hline PNS & 5 & 13,16 \\
Swasta & 9 & 23,69 \\
Petani & 4 & 10,53 \\
Pedagang & 6 & 15,78 \\
Lain-lain (IRT) & 14 & 36,84 \\
\hline Jumlah & $\mathbf{3 8}$ & $\mathbf{1 0 0}$
\end{tabular}

Sumber : Data Primer Tahun 2019

Berdasarkan tabel 4.2 menunjukkan bahwa responden yang memiliki pekerjaan sebagai PNS 5 orang $(13,16 \%)$ yang bekerja sebagai Wiraswasta 9 orang $(23,69 \%)$ yang bekerja sebagai petani 4 orang $(10,53 \%)$ yang bekerja sebagai pedagang 6 orang $(15,78 \%)$ dan sisanya yang tidak bekerja atau lain-lain (IRT) 14 orang $(36,84 \%)$.

Tabel 4.3 Distribusi Frekuensi Pengguna KB Suntik 3 Bulan (Depo Progestin) Berdasarkan
Pendidikan di Puskesmas Bontobahari Kec. Bontobahari Kab. Bulukumba.

\begin{tabular}{ccc}
\hline Pendidikan & $(\mathbf{F})$ & $\mathbf{( \% )}$ \\
\hline Tidak tamat SD/Tidak sekolah & 0 & 0 \\
SD & 2 & 5,27 \\
SMP & 6 & 15,78 \\
SMA & 23 & 60.53 \\
Perguruan Tinggi & 7 & 18,42 \\
\hline Jumlah & $\mathbf{3 8}$ & $\mathbf{1 0 0}$ \\
\hline
\end{tabular}

Sumber : Data Primer Tahun 2019

Berdasarkan tabel 4.3 menunjukkan bahwa responden yang tingkat pendidikan tidak tamat SD/tidak sekolah 0 orang (0\%), SD sebanyak 2 orang $(5,27 \%)$, SMP sebanyak 6 orang (15,78\%), SMA sebanyak 23 orang $(60,53 \%)$ dan Perguruan tinggi sebanyak 7 orang $(18,42 \%)$.

Tabel 4.4 Distribusi Frekuensi Responden Berdasarkan Pengetahuan Ibu Tentang KB Suntik 3 Bulan (Depo Progestin) Berdasarkan Pendidikan di Puskesmas Bontobahari Kec. Bontobahari Kab. Bulukumba.

\begin{tabular}{ccc}
\hline Tingkat Pengetahuan & $\mathbf{( F )}$ & $\mathbf{( \% )}$ \\
\hline Baik & 15 & 39,48 \\
Cukup & 13 & 34,21 \\
Kurang & 10 & 26,31 \\
\hline Jumlah & $\mathbf{3 8}$ & $\mathbf{1 0 0}$ \\
\hline
\end{tabular}

Sumber : Data Primer Tahun 2019

Berdasarkan tabel 4.4 dapat dilihat bahwa tingkat pengetahuan ibu tentang $\mathrm{KB}$ suntik 3 bulan depo progestin yang paling banyak pada kategori baik sebanyak 15 responden (39,48\%), kategori cukup sebanyak 13 responden $(34,21 \%)$ dan paling sedikit pada kategori kurang yaitu sebanyak 10 responden $(23,3 \%)$.

\section{2) Variabel Penelitian}

Tabel 4.5 Distribusi Frekuensi Pengetahuan Ibu Berdasarkan Pengertian KB Suntik 3 Bulan (Depo Progestin) di Puskesmas Bontobahari Kec. Bontobahari Kab. Bulukumba.

\begin{tabular}{ccc}
\hline Pengertian & $(\mathbf{F})$ & $\mathbf{( \% )}$ \\
\hline Baik & 31 & 81,58 \\
Cukup & 5 & 13,16 \\
Kurang & 2 & 5,27 \\
\hline Jumlah & $\mathbf{3 8}$ & $\mathbf{1 0 0}$ \\
\hline Sumber : Data Primer Tahun 2019 &
\end{tabular}


Berdasarkan tabel 4.5 menunjukkan bahwa dari 38 reponden yang diteliti didapatkan yang berpengetahuan baik 31 orang $(81,58 \%)$, cukup 5 orang $(13,16 \%)$ dan kurang 2 orang $(5,27 \%)$ tentang pengertian KB suntik 3 bulan Depo Progestin di Puskesmas Bontobahari Kec. Bontobahari Kab. Bulukumba

Tabel 4.6 Distribusi Frekuensi Pengetahuan Ibu Berdasarkan Waktu Penggunaan KB Suntik 3 Bulan (Depo Progestin) di Puskesmas Bontobahari Kec. Bontobahari Kab. Bulukumba.

\begin{tabular}{ccc}
\hline Waktu Penggunaan & $(\mathbf{F})$ & $\mathbf{( \% )}$ \\
\hline Baik & 29 & 76,31 \\
Cukup & 6 & 15,79 \\
Kurang & 3 & 7,90 \\
\hline Jumlah & $\mathbf{3 8}$ & $\mathbf{1 0 0}$ \\
\hline
\end{tabular}

Sumber : Data Primer Tahun 2019

Berdasarkan tabel 4.6 menunjukkan bahwa dari $38 \mathrm{ibu}$ responden yang diteliti didapatkan yang berpengetahuan baik 29 orang $(76,31 \%)$, cukup 6 orang $(15,79 \%)$ dan kurang 3 orang $(7,90 \%)$ tentang waktu penggunaan KB suntik 3 bulan Depo Progestin di Puskesmas Bontobahari Kec. Bontobahari Kab. Bulukumba.

Tabel 4.7 Distribusi Frekuensi Pengetahuan Ibu Berdasarkan Efek Samping KB Suntik 3 Bulan (Depo Progestin) di Puskesmas Bontobahari Kec. Bontobahari Kab. Bulukumba.

\begin{tabular}{ccc}
\hline Efek Samping & $(\mathbf{F})$ & $\mathbf{( \% )}$ \\
\hline Baik & 29 & 76,31 \\
Cukup & 6 & 15,79 \\
Kurang & 3 & 7,90 \\
\hline Jumlah & $\mathbf{3 8}$ & $\mathbf{1 0 0}$ \\
\hline
\end{tabular}

Sumber : Data Primer Tahun 2019

Berdasarkan tabel 4.7 menunjukkan bahwa dari 38 responden yang diteliti didapatkan yang berpengetahuan baik 29 orang $(76,31 \%)$, cukup 6 orang $(15,79 \%)$ dan kurang 3 orang $(7,90 \%)$ tentang efek samping KB suntik 3 bulan Depo Progestin di Puskesmas Bontobahari Kec. Bontobahari Kab. Bulukumba.

Tabel 4.8 Distribusi Frekuensi Pengetahuan Ibu Berdasarkan Keuntungan KB Suntik 3 Bulan
(Depo Progestin) di Puskesmas Bontobahari Kec. Bontobahari Kab. Bulukumba.

\begin{tabular}{ccc}
\hline Keuntungan & $(\mathbf{F})$ & $\mathbf{( \% )}$ \\
\hline Baik & 30 & 78,94 \\
Cukup & 8 & 21,06 \\
Kurang & 0 & 0 \\
\hline Jumlah & $\mathbf{3 8}$ & $\mathbf{1 0 0}$ \\
\hline
\end{tabular}

Sumber : Data Primer Tahun 2019

Berdasarkan tabel 4.8 menunjukkan bahwa dari 38 responden yang diteliti didapatkan yang berpengetahuan baik 30 orang $(78,94 \%)$, cukup 8 orang $(21,06 \%)$ dan kurang 0 orang (0\%) tentang keuntungan $\mathrm{KB}$ suntik 3 bulan Depo Progestin di Puskesmas Bontobahari Kec. Bontobahari Kab. Bulukumba.

Tabel 4.9 Distribusi Frekuensi Pengetahuan Ibu Berdasarkan Kerugian KB Suntik 3 Bulan (Depo Progestin) di Puskesmas Bontobahari Kec. Bontobahari Kab. Bulukumba.

\begin{tabular}{ccc}
\hline Kerugian & $(\mathbf{F})$ & $\mathbf{( \% )}$ \\
\hline Baik & 30 & 78,95 \\
Cukup & 7 & 18,42 \\
Kurang & 1 & 2,63 \\
\hline Jumlah & $\mathbf{3 8}$ & $\mathbf{1 0 0}$ \\
\hline
\end{tabular}

Sumber : Data Primer Tahun 2019

Berdasarkan tabel 4.9 menunjukkan bahwa dari 38 responden yang diteliti didapatkan yang berpengetahuan baik 30 orang $(78,94 \%)$, cukup 7 orang $(18,95 \%)$ dan kurang 1 orang $(5,27 \%)$ tentang kerugianKB suntik 3 bulan Depo Progestin di Puskesmas Bontobahari Kec. Bontobahari Kab. Bulukumba.

\section{PEMBAHASAN}

1. Tingkat Pengetahuan Ibu Tentang KB Suntik 3 Bulan (Depo Progestin)

Berdasarkan hasil penelitian menunjukkan bahwa secara keseluruhan akseptor KB suntik 3 bulan (depo progestin) di Puskesmas Bontobahari Kec. Bontobahari Kab. Bulukumba memiliki tingkat pengetahuan tentang $\mathrm{KB}$ suntik 3 bulan (depo progestin) mayoritas kategori baik sebanyak 15 orang $(39,48 \%)$. Ibu yang berpengetahuan baik tentang KB suntik 3 bulan dan paham tentang pengertian, waktu penggunaan, efek samping, keuntungan \& kerugian. 
Pengetahuan merupakan hasil dari tahu sebagai akibat proses pengindraan terhadap obyek tertentu melalui panca indera dan sebagain besar pengetahuan manusia diperoleh dari mata dan telinga, dengan pengetahuan memungkinkan seseorang untuk dapat memecahkan masalah yang dihadapinya dimana pengetahuan tersebut diperoleh dari pengalaman langsung maupun pengalaman orang lain (Notoatmodjo, 2012).

Berdasarkan karakteristik umur, tingkat pengetahuan ibu tentang $\mathrm{KB}$ suntik 3 bulan (depo progestin) di Puskesmas Bontobahari Kec. Bontobahari Kab. Bulukumba mayoritas responden berumur 20-35 tahun yaitu sebanyak 20 orang (52,63\%). Saifuddin (2010) menulis indikasi KB suntik 3 bulan adalah usia reproduksi, usia reproduktif sehat seorang wanita adalah antara umur 20-35 tahun dan ini menunjukkan bahwa sebagian besar responden termasuk dalam kategori reproduktif. Ibu yang menggunakan $\mathrm{KB}$ suntik 3 bulan (depo progestin) umur 20-35 tahun untuk menunda kehamilan. Salah satu faktor yang mempengaruhi pengetahuan adalah umur, semakin bertambahnya umur maka akan semakin berkembang pula daya tangkap dan pola pikiran sehingga pengetahuan yang diperoleh juga akan semakin membaik \& bertambah (Budiman dan Riyanto, 2013).

Berdasarkan karakteristik pendidikan, tingkat pengetahuan ibu tentang $\mathrm{KB}$ suntik 3 bulan (depo progestin) di Puskesmas Bontobahari Kec. Bontobahari Kab. Bulukumba mayoritas pendidikan SMA sebanyak 23 orang $(60,53 \%)$. Pendidikan merupakan salah satu faktor yang mempengaruhi pengetahuan. Pendidikan adalah proses perubahan sikap dan perilaku seseorang atau kelompok dan merupakan usaha mendewasakan manusia melalui upaya pengajaran dan pelatihan. Pada umumnya semakin tinggi pendidikan seseorang maka semakin cepat menerima dan memahami suatu informasi sehingga pengetahuan yang dimilki juga semakin tinggi (Budiman dan Riyanto, 2013).

Berdasarkan karakteristik pekerjaan, tingkat pengetahuan ibu tentang $\mathrm{KB}$ suntik 3 bulan (depo progestin) di Puskesmas Bontobahari Kec. Bontobahari Kab. Bulukumba mayoritas ibu bekerja sebagai ibu rumah tangga (IRT) yaitu sebanyak 14 orang $(36,84 \%)$. Salah satu faktor pembentuk pengetahuan seseorang adalah lingkungan sosial termasuk di dalamnya lingkungan kerja. Pekerjaan seseorang sangat sangat berpengaruh terhadap proses mengakses informasi yang dibutuhkan terhadap salah satu obyek (Budiman dan Riyanto, 2013).

\section{Tingkat Pengetahuan Ibu Tentang Pengertian KB Suntik 3 Bulan (Depo Progestin)}

Berdasarkan hasil penelitian pada tabel 4.5 tingkat pengetahuan ibu tentang pengertian KB suntik 3 bulan (depo progestin) di Puskesmas Bontobahri Kec. Bontobahari Kab. Bulukumba sebagian besar adalah kategori baik sebanyak 31 orang $(78,94 \%)$. Dalam penelitian ini dengan pengetahuan cukup terdapat 5 orang $(13,16 \%)$ tentang pengertian $\mathrm{KB}$ suntik 3 bulan (depo progestin) disebabkan oleh faktor pekerjaan, dimana responden memiliki pengetahuan cukup adalah petani, ibu yang bekerja sebagai petani tidak memiliki waktu yang cukup untuk berinteraksi dengan orang lain di lingkungan dan mengakses informasi karena ibu yang bekerja sebagai petani mulai dari pagi sampai dengan sore hari dia menghabiskan waktunya di lahan pertaniannya. Hasil penelitian ini sejalan dengan penelitian yang dilakukan oleh Tyas Yesiana Putri (2017) yang menunjukkan bahwa tingkat pengetahuan tentang pengertian kategori cukup berstatus Petani.Hasil penelitian ini dapat disimpulkan bahwa dari pekerjaan seseorang sangat mempengaruhi kualitas tingkat pengetahuan untuk mengakses informasi yang dibutuhkan terhadap salah satu obyek, karena dengan pekerjaan bisa menentukan sedikit banyaknya pengalaman serta berinteraksi dengan orang banyak di lingkungan kerjanya.

\section{Tingkat Pengetahuan Ibu Tentang Waktu Penggunaan KB Suntik 3 Bulan (Depo Progestin)}

Berdasarkan hasil penelitian pada tabel 4.6 tingkat pengetahuan ibu tentang waktu 
penggunaan di Puskesmas Bontobahari Kec. Bontobahari Kab. Bulukumba sebagian besar dalam kategori baik yaitu sebanyak 29 orang $(76,31 \%)$. Dalam penelitian ini terdapat 3 orang $(7,90 \%)$ yang memiliki tingkat pengetahuan yang kurang disebabkan oleh faktor pendidikan. Responden yang berpengetahuan kurang berstatus pendidikan akhir yaitu SD. Hasil penelitian ini sejalan dengan penelitian yang dilakukan oleh Oktiami (2014) yang menunjukan bahwa tingkat pengetahuan tentang waktu penggunaan kategori kurang berpendidikan. Hasil penelitian ini dapat disimpulkan bahwa pendidikan memiliki pengaruh yang besar untuk memperoleh pengetahuan yang baik, semakin tinggi pendidikan seseorang maka semakin cepat menerima dan memahami suatu informasi dan begitu juga sebaliknya seseorang yang berpendidikan rendah, akan menghambat seseorang untuk menerima dan memahami informasi yang baru.

4. Tingkat Penegtahuan Ibu Tentang Efek Samping KB Suntik 3 Bulan (Depo Progestin)

Berdasarkan hasil penelitian pada tabel 4.7 tingkat pengetahuan ibu tentang efek samping di Puskesmas Bontobahari Kec. Bontobahari Kab. Bulukumba sebagian besar dalam kategori baik yaitu sebanyak 29 orang $(76,31 \%)$. Dalam penelitian ini terdapat 3 orang $(7,90 \%)$ yang memiliki tingkat pengetahuan yang kurang disebabkan oleh faktor pendidikan. Responden yang berpengetahuan kurang berstatus pendidikan akhir SD. Hasil penelitian ini sejalan dengan penelitian yang dilakukan oleh Dedah Umilah Maswatu (2017) yang menunjukan bahwa tingkat pengetahuan tentang efek samping kategori kurang berpendidikan. Hasil penelitian ini dapat disimpulkan bahwa kurangnya pendidikan seseorang akan menghambat untuk mendapatkan infomasi yang baru sehingga sulit untuk menerima suatu ajaran baru dan nilai yang baru untuk diterapkan didalam kehidupan sehari-hari.

\section{Tingkat Penegtahuan Ibu Tentang Keuntungan KB Suntik 3 Bulan (Depo Progestin)}

Berdasarkan hasil penelitian pada tabel 4.8, tingkat pengetahuan tentang keuntungan $\mathrm{KB}$ suntik 3 bulan (depo progestin) di Puskesmas Bontobahari Kec. Bontobahari Kab. Bulukumba sebagian besar adalah kategori baik yaitu sebanyak 30 orang $(78,94 \%)$. Dalam penelitian ini terdapat 8 orang $(21,06 \%)$ yang memiliki tingkat pengetahuan cukup tentang $\mathrm{KB}$ suntik 3 bulan (depo progestin). Tingkat pengetahuan cukup tentang KB suntik3 bulan (depo progestin) disebabkan oleh faktor pendidikan.Responden yang berpengetahuan cukup berstatus pendidikan akhir SMP.Hasil penelitian ini sejalan dengan penelitian yang dilakukan oleh Oktiami (2014) yang menunjukan bahwa tingkat pengetahuan tentang keuntungan kategori kurang berpendidikan.Hasil penelitian ini dapat disimpulkan bahwa pemikiran seseorang di pengaruhi oleh pendidikan, semakin tinggi pendidikan seseorang maka semakin baik pula untuk mengolah informasi yang diperolehnya untuk mengambil suatu keputusan.

\section{Tingkat Penegtahuan Ibu Tentang Kerugian KB Suntik 3 Bulan (Depo Progestin)}

Berdasarkan hasil penelitian pada tabel 4.9, tingkat pengetahuan ibu tentang keuntungan KB suntik 3 bulan (depo progestin) di Puskesmas Bontobahari Kec. Bontobahari Kab. Bulukumba mayoritas adalah kategori baik yaitu sebanyak 30 orang $(78,95 \%)$. Dalam penelitian ini terdapat 1 responden $(2,63 \%)$ yang memiliki pengetahuan kurang tentang kerugian KB suntik 3 bulan. Tingkat pengetahuan yang kurang disebabkan oleh faktor umur.Responden yang memiliki pengetahuan kurang adalah umur 18 tahun. Hasil penelitian ini sejalan dengan penelitian yang dilakukan oleh Nur Aeni (2015) yang menunjukan bahwa tingkat pengetahuan tentang kerugian kategori usia masih sangat muda. Hasil penelitian ini dapat disimpulkan bahwa umur yang matang (Dewasa) akan lebih mudah menerima informasi yang diperoleh 
dari pengalaman langsung maupun dari pengalaman oleh orang lain, dibandingkan dengan umur yang masih muda atau belum terbilang dewasa akan sulit untuk menerima informasi yang baru dan mempengaruhi pola berfikirnya untuk mengambil suatu keputusan.

\section{KESIMPULAN DAN SARAN}

\section{A. Kesimpulan}

1. Hasil penelitian menunjukkan bahwa Ibu akseptor KB suntik 3 bulan (depo progestin) di Puskesmas Bontobahari Kec. Bontobahari Kab. Bulukumba memiliki pengetahuan baik sebanyak 15 orang $(39,48 \%)$, \%).

2. Pengetahuan ibu tentang pengertian KB suntik 3 bulan (depo progestin) di Puskesmas Bontobahari Kec. Bontobahari Kab. Bulukumba kategori baik 31 orang $(81,58 \%)$.

3. Pengetahuan ibu tentang waktu penggunaan $\mathrm{KB}$ suntik 3 bulan (depo progestin) di Puskesmas Bontobahari Kec. Bontobahari Kab. Bulukumba kategori baik 29 orang (76,31\%).

4. Pengetahuan ibu tentang efek samping KB suntik 3 bulan (depo progestin) di Puskesmas Bontobahari Kec. Bontobahari Kab. Bulukumba kategori baik 29 orang (76,31\%).

5. Pengetahuan ibu tentang keuntungan KB suntik 3 bulan (depo progestin) di Puskesmas Bontobahari Kec. Bontobahari Kab. Bulukumba kategori baik baik 30 orang $(78,94 \%)$.

6. Pengetahuan ibu tentang kerugian KB suntik 3 bulan (depo progestin) di Puskesmas Bontobahari Kec. Bontobahari Kab. Bulukumba kategori baik baik 30 orang (78,94\%).

\section{B. Saran}

1. Bagi Puskesmas

Diharapkan hasil penelitian ini dapat menjadi masukan bagi pihak tim kesehatan di Puskesmas untuk mengetahui pengetahuan ibu tenang $\mathrm{KB}$ suntik 3 bulan (depo progestin)

2. Bagi peneliti selanjutnya

Diharapkan hasil penelitian ini dapat menjadi bahan pustaka, menambah wawasan dan pengetahuan bagi mahasiswa lain yang ingin melakukan penelitian lanjut tentang gambaran pengetahuan ibu tentang KB suntik 3 bulan (depo progestin)

3. Bagi institusi pendidikan
Diharapkan hasil penelitian ini dapat menjadi salah satu bahan masukan bagi institusi untuk pengembangan program pendidikan sehingga dapat memberikan pelayanan yang actual dan profesional pada masyarakat.

4. Bagi peneliti

Diharapkan hasil penelitian ini dapat menambah pengetahuan peneliti mengenai penelitian lapangan dan menambah informasi peneliti mengenai pemilihan terhadap memilih metode kontrasepsi untuk mengatur jarak kelahiran.

\section{DAFTAR PUSTAKA}

Affandi B. dkk.(2014). Buku Panduan Praktis Pelayanan Kontrasepsi.Edisi 3. Jakarta: PTBina Pustaka Sarwono Prawirohardjo

Arikunto, S. (2013).Prosedur Penelitian: Suatu Pendekatan Praktik. Jakarta: Rineka Cipta. (VARIABEL)

Astuti, DY, (2010). Kontrasepsi Suntik. Diakses dari http://www.ktiskripsi.com/2010/05/kti-kbsuntik.html.pada tanggal 30 November 2018.

Ayu. 2006. Ilmu Kebidanan Penyakit Kandungan Dan KB. Jakarta : EGC.

Budiman \& Riyanto A. 2013. Kapita Selekta kuisioner Pengetahuan Dan SikapDalam Penelitian Kesehatan.Jakarta : Salemba Medika pp 66-69.

Kementrian Kesehatan RI, 2017. Profil Kesehatan Indonesia.Jakarta, (online), http://www.pusdatin.kemkes.go.id/resource s/download/pusdatin/profil-kesehatanindonesia/Data-dan-Informasi Profil-

Kesehatan-Indonesia-2017.pdf/diakses pada tanggal 20 November 2018.

Kamaruddin M., Sumarni, Ganie A.H., Misnawaty, Misriyani, Rivandi A., Purnamasari D., (2020), Faktor-Faktor yang Berhubungan dengan Kurangnya Minat Ibu Terhadap Penggunaan Metode Kontrasepsi Implant di Wilayah Puskesmas Ponre Kecamatan Gantarang Kabupaten Bulukumba, Medika Alkhairaat : Jurnal 
Penelitian Kedokteran dan Kesehatan, 1(2): 156-166.

Notoatmodjo, S, (2012). Metodologi Penelitian Kesehatan, Rineka Cipta, Jakarta

Nur, Aeni. (2015). Gambaran Tingkat Pengetahuan Ibu Tentang KB Suntik 3 Bulan Di Klinik Pelita Hati Bantul Yogyakarta. Jurnal Kebidanan.Vol 5.No 7. Hal 8-9

Oktiami, Devi. (2014). Gambaran Tingkat Pengetahuan Ibu Akseptor KB Suntik tentang KB Hormonal 3 Bulan di Puskesmas Sedayu II Bantul Yogyakarta.Jural Kebidanan.Vol 7. No 2. Hal 13-15

Hidayat, A.A, (2014). Metode penelitian keperawatan dan teknis analisis data.Jakarta : Salemba Medika

Saifuddin, Abdul Bari., dkk (ed). (2010). Buku Panduan Praktis Pelayanan Kontrasepsi.Jakarta : Yayasan Bina Pustaka Sarwono Prawirohardjo.
Umilah, Dedah Maswatu. (2017). Gambaran Tingkat Pengetahuan Akseptor KB Suntik Tentang Efek Samping Kontrasepsi Suntik Progestin Di Puskesmas Gamping 1 Sleman Yoghyakarta

Yesiana, Tyas Dwi Saputri. (2017). Gambaran Pengetahuan Ibu Akseptor KB Suntik 3 Bulan Tentang Kontrasepsi Suntik 3 Bulan Di Puskesmas Kretek Bantul Yogyakarta. 